\title{
Rarely Observed Sports Injuries: Two Case Reports
}

\author{
Erdal Uzun', Turan Bilge Kızkapan', Emre Bülbül²
}

'Department of Orthopedics and Traumatology, Erciyes University Faculty of Medicine, Kayseri, Turkey 2Department of Emergency Medicine, Erciyes University Faculty of Medicine, Kayseri, Turkey

\section{ABSTRACT}

Introduction: Avulsion fractures of the anterior inferior iliac spine (AlIS), anterior superior iliac spine (ASIS), tuberositas ischii, iliac apophysis, and reflected head of rectus occur in children because of apophyseal cartilage failure. In this report, we present two cases of avulsion fractures of the AllS and tuberositas ischii.

Case Report: Two amateur football players who are 15 and 16 years old presented to an emergency clinic with groin pain after kicking the ball during a football match. Their passive hip motions were normal, whereas active hip motions were painful and right groins were painful during deep palpation. Radiological examinations revealed avulsion fracture of AllS in one patient and avulsion fracture of the tuber ischium in the other patient. We started analgesic treatment in both patients with them lying in the supine position with the hip in 45 degree flexion. Patients were mobilized after 2 weeks with elbow crutches. Four weeks later, we started active hip motions.

Conclusion: Avulsion fractures of the ASIS and tuber ischiadicum are rare cases in adolescent sportsmen. These injuries can easily be overlooked or misdiagnosed. A delay in diagnosis may cause hip pain and lower the performance of sportsmen.

Keywords: Avulsion fracture, apophysis, adolescent

Received:06.12.2014 Accepted:29.07.2015

\section{Introduction}

There are many studies about avulsion fractures of the pelvic ring that occur on the apophysis of the anterior inferior iliac spina (AllS), anterior superior iliac spina (ASIS), tuber ischiadicum, iliac crest, and symphysis pubis. Avulsion injuries, including those to the pelvic ring, often can be seen in adolescent sportsmen, whereas they are less frequently reported in adults and patients with cerebral palsy $(1,2)$. Apophysis avulsion fractures in young sportsmen occur because of over-muscle contractions in muscle-bone connections (3). ASIS and AllS avulsion fractures are frequently seen in sportsmen (4). We aimed to report the conservative therapy results of two patients with avulsion fractures of the AllS and tuber ischiadicum.

\section{Case Reports}

An amateur football player, 15 years of age, presented to an emergency clinic with groin pain after shooting during a football match. His passive and active hip motions were both painful, and there was extreme pain on his tuber ischiadicum during palpation. Radiological examinations showed avulsion fracture of the tuber ischiadicum (Figure 1). The other patient was a 16-year-old amateur football player. His passive hip motions were full, whereas active hip motions and right groin were particularly painful during deep palpation. Radiological examinations revealed avulsion fracture of AlIS (Figure 2). We started analgesic treatment in both patients and gave lying position while hip was in 45 degree flexion. Patients were mobilized after 2 weeks with elbow crutches. Four weeks later, we started active hip motions. We took a detailed informed consent from both patients.

\section{Discussion}

Apophysis is a special ossification center next to the immature skeletal system, near joints, and lets the bones I growth peripherally. Also, primarily, they are growth plates that respond to tensile stress. Large muscles and muscle groups originate or connect to bones from these locations. Sudden contractions of these muscles can cause avulsion fractures (5). Pelvic apophysis ossification is seen during the adolescent period; therefore, avulsion fractures are seen more often during this period (6). In our study, both patients were in the adolescent age group. Although the avulsion fractures of the ischium are caused by contractions of hamstrings and adductors during hip flexion, AllS and ASIS avulsions are caused by the contractions of rectus femoris, Sartorius, or tensor fascia lata during hip extension or knee flexion. AllS, 


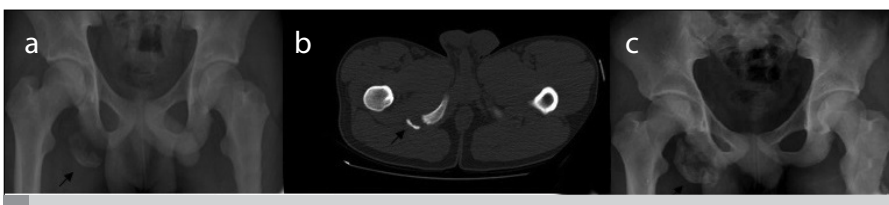

Figure 1. a-c. Tuber ischium avulsion fracture on pelvic anteriorposterior radiography and pelvic tomography $(a, b)$. Pelvic anteriorposterior radiography after 1 month (c).*

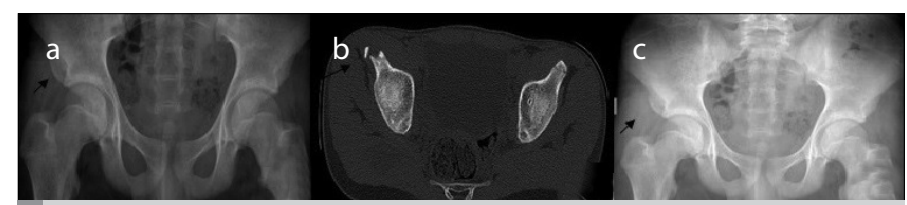

Figure 2. a-c. AllS avulsion fracture in pelvic anterior-posterior radiography and pelvic tomography $(\mathrm{a}, \mathrm{b})$. Pelvic anterior-posterior radiography after 1 month (c).*

ASIS, and tuber ischiadicum are the most common anatomic locations of apophysis injury (7). Avulsion fracture of AllS is the result of uncoordinated, powerful, sudden contracture of the rectus femoris muscle (8). Generally, it is seen in the early adolescent period or active people. Patients generally describe a "pop" or "snap" sound with acute pelvic avulsion fracture. Subsequently, a tense pain and muscle function defect would develop. The radiologic appearance of the avulsion fracture of AllS is characteristic. Severed fracture would generally be in the shape of a crescent or triangle. Avulsed part of the fracture would generally be displaced to inferior minimally (2). The most common complications in patients with conservative therapy are exocytosis, non-union, and resistant pain. Surgery should be planned in patients who wish to have an early return to their normal activities, fracture bigger than $2 \mathrm{~cm}$, non-union, or exocytosis. Conservative therapy includes non-steroid anti-inflammatory use and bed rest in the early period, followed by physical therapy in a few weeks. After the first week, mobilization can be allowed with crutches (9). Any activity should be avoided in cases with severe pain (5). Complete recovery is reported between 3 weeks and 4 months (8).

\section{Conclusion}

Avulsion fractures of the ASIS and tuber ischiadicum are rare cases in adolescent sportsmen. These injuries can easily be overlooked or misdi- agnosed. A delay in diagnosis may cause hip pain and lower the performance of sportsmen.

Ethics Committee Approval: Ethics Committee approval has been received.

Informed Consent: Written informed consent was obtained from patient who participated in this study.

Peer-review: Externally peer-reviewed.

Author contributions: Concept - E.U.; Design - E.U., T.B.K.; Supervision E.U., E.B.; Resource - E.U., T.B.K.; Materials - E.U., E.B.; Data Collection and/or Processing - E.U., T.B.K.; Analysis and/or Interpretation - E.U., T.B.K.; Literature Search - E.U., E.B.; Writing - E.U.; Critical Reviews - T.B.K., E.B.

Conflict of Interest: No conflict of interest was declared by the authors.

Financial Disclosure: The authors declared that this study has received no financial support.

\section{References}

1. Bolgla LA, jones DL, Keskula DR, Duncan JB. Hip pain in a high school football palyer: A case report. J AthI Train 2001; 36: 81-4

2. Metzmaker JN, Pappas AM. Avulsion fractures of the pelvis. Am J Sports Med 1985; 13: 349-58. [CrossRef]

3. Roy S, Irvin R. Sports medicine: prevention, evaluation, management, and rehabilitation. 1 st ed. New jersey: Prentice-Hall; 1983.

4. Gomez JE. Bilateral anterior inferior iliac spine avulsion fractures. Med Sci sports Exerc 1996; 28: 161-4. [CrossRef]

5. Lambert MJ, Flinger DJ. Avulsion of the iliac crest apophysis: a rare fracture in adolescent athletes. Ann Emerg Med 1993; 22: 1218-20. [CrossRef]

6. White KK, Williams SK, Mubarak SJ. Definition of two types of anterior superior iliac spine avulsion fractures. J Pediatr Orthop 2002; 22: 578-82. [CrossRef]

7. Akova B, Okay. Avulsion of the ischial tuberosity in a young soccer player: six years follow-up: J Sports Sci Med 2002; 1: 27-30.

8. Rajasekhar C, Kumar KS, Bhamra MS. Avulsion fractures of the anterior inferior iliac spine: the case for surgical intervention. Int Orthop 2001; 24: 364-5. [CrossRef]

9. Irving $\mathrm{MH}$. Exostosis formation after traumatic avulsion of the anterior inferior iliac spine. Report of two cases. J Bone Joint Surg 1964; 46: 720-2. 